\title{
O AMOR E O STALKEADOR: NOVOS RECURSOS PARA A VIGILÂNCIA NAS REDES SOCIAIS
}

\author{
LOVE AND STALKING: NEW FEATURES FOR SURVEILLANCE IN SOCIAL NETWORKS \\ EL AMOR Y EL STALKEADOR: NUEVOS RECURSOS PARA LA VIGILANCIA EN LAS REDES \\ SOCIALES
}

\author{
Jacqueline de Oliveira Moreira* \\ Nádia Laguárdia de Lima* \\ Márcia Stengel ${ }^{* * *}$ \\ Hugo Leonardo Goes Bento ${ }^{* * *}$ \\ Lucas Ferreira Pedro dos Santos ${ }^{* * * *}$ \\ Gabriela Bouzada Costa*****
}

\begin{abstract}
RESUMO
O objeto de estudo deste artigo é o fenômeno do "stalkear", que consiste na vigilância permanente da pessoa amada por meio das postagens nas redes sociais virtuais. Fundamentados na teoria psicanalítica, acredita-se que as relações virtuais são marcadas pelo imaginário da completude. Com base nos mitos dos Andróginos e de Diotima, em "O Banquete", de Platão, discute-se o amor, que se caracterizaria pela busca de uma unidade perdida no primeiro mito, e como oscilação e falta no segundo. Na contemporaneidade, a dimensão do outro como a dimensão da falta aparece eclipsada, acarretando consequências ao campo amoroso. A tecnologia virtual favorece a ilusão da completude quando rompe as distâncias entre os sujeitos, já que é possível se falar a qualquer hora e local. O fenômeno do "stalkear" nas redes sociais aparece facilitado pela própria lógica de funcionamento das redes e das possibilidades que elas abrem aos sujeitos.
\end{abstract}

Palavras-chave: Relações amorosas. Redes sociais virtuais. Stalkear. Psicanálise.

\footnotetext{
Texto recebido em 14 de janeiro de 2014 e aprovado para publicação em 20 de junho de 2016.

Doutora em Psicologia Clínica pela PUC SP, mestra em Filosofia pela Universidade Federal e Minas Gerais (UFMG), Programa de Pós-Graduação em Psicologia da PUC Minas (M/D), psicanalista, bolsista PQ2 do CNPq. E-mail: jackdrawin@yahoo.com. br.

** Doutora em Educação pela UFMG, psicóloga formada pela UFMG, Departamento de Psicologia da UFMG, Programa de Pós-Graduação em Psicologia da UFMG. E-mail: nadia.laguardia@gmail.com.

*** Pós-doutora em Educação pela UFMG, doutora em Ciências Sociais pela UERJ, Programa de Pós-Graduação em Psicologia da PUC Minas (M/D). E-mail: marciastengel@gmail.com.

${ }^{* * * *}$ Mestre em Psicologia PUC Minas, bolsista de mestrado Fapemig, psicólogo formado pela Universidade Fumec (MG).

${ }^{* * * * *}$ Mestre em Psicologia pela PUC Minas, bolsista de mestrado CNPq, psicólogo formado pela UFMG. E-mail: lucasfpsantos@ gmail.com.

${ }^{* * *+* *+}$ Graduanda em Psicologia pela UFMG. E-mail: gabihcosta@gmail.com.
} 


\begin{abstract}
The object of this article is the phenomenon of stalking, which consists of permanent surveillance of the beloved one through their posts in virtual social networks. Grounded in psychoanalytic theory, we believe that virtual relationships are marked by the imagery of completeness. Based on the myths of Androgyny and Diotima in Plato's "The Symposium”, we discuss love, which is characterized by the search for a lost unity in the first myth, and by oscillation and absence in the second. In contemporary times, the measure of the other as the dimension of absence is eclipsed, resulting in consequences for the field of love. Virtual technology fosters the illusion of completeness when it breaks with the distances between the subject, since its users have the opportunity to get in touch with one another at any time and place. The phenomenon of stalking on social networks is facilitated by the logic of how networks work and the possibilities they open to the subjects.
\end{abstract}

Keywords: Love relations. Virtual social networks. Stalking. Psychoanalysis.

\title{
RESUMEN
}

El objeto de este artículo es el fenómeno de stalkear que consiste en la vigilancia permanente de la persona amada a través de mensajes en las redes sociales virtuales. Con base en la teoría psicoanalítica, creemos que las relaciones virtuales están marcadas por el imaginario de la exhaustividad. A partir de los mitos de los Andróginos y de Diotima en "El Banquete" de Platón, se discute el amor, que se caracterizaría por la búsqueda de una unidad perdida en el primer mito, y cómo oscilación y falta en el segundo. En la época contemporánea la dimensión del otro como la dimensión de la falta aparece eclipsada, dando como resultado consecuencias en el campo amoroso. La tecnología virtual fomenta la ilusión de plenitud cuando rompe con las distancias entre los sujetos, ya que se puede hablar a cualquier hora y lugar. El fenómeno del stalkear en las redes sociales aparece facilitado por la propia lógica de funcionamiento de las redes y de las posibilidades que ellas abren a los individuos.

Palabras clave: Relaciones amorosas. Social virtual redes. Stalkear. Psicoanálisis.

\section{REFLEXÕES SOBRE O AMOR}

$\mathrm{N}$ este texto, pretende-se refletir sobre um fenômeno presente no campo das relaçõos amorosas: a perseguição. Esse fenômeno não é novo, todavia, com o advento e exacerbação dos dispositivos de redes sociais, essa ação de perseguição da pessoa amada adquire novos contornos, possibilidades e desenhos. 
Sabemos que o tema subjacente à reflexão sobre a perseguição é o amor, sentimento que tem sido objeto de estudo, fascínio e medo ao longo da história da humanidade. Talvez a primeira reflexão sobre o tema do amor tenha aparecido nos escritos do pré-socrático Empédocles, que propôs os quatro elementos essenciais à constituição de tudo, a saber: o fogo, a água, a terra e o ar. Estes são colocados em constante união e separação pela força do amor e do ódio. É importante enfatizar que seria uma leitura ingênua aproximar rapidamente a força do amor a uma positividade e a do ódio a uma negatividade. A atração exercida pelo amor pode combinar dois elementos com fortes potenciais destrutivos; por exemplo, a união do fogo com o ar.

Ainda que não tenha sido a primeira, a reflexão mais famosa sobre o amor se encontra no clássico texto de Platão (2005), O banquete. Nele se encontram diferentes definiçóes de amor, sendo as duas mais importantes as proferidas pelas bocas de Aristófanes e de Sócrates. O Mito dos Andróginos, apresentado por Aristófanes, revela que o amor surge do corte de uma unidade perfeita original. Nesse caso, o amor expressa a busca por uma unidade perdida, almejando, assim, a reconstrução da perfeita união de uma célula completa e o fim da falta. A proposta de Sócrates, que é creditada à sacerdotisa Diotima, revela uma definição de amor marcada pelo paradoxo, pela situação de oscilação, porque o amor (Eros) seria filho de uma mortal (Penúria) com um deus (Abundância). Assim, nessa perspectiva, o amor é divino e vil, e possibilita a vivência de elevação e queda.

Não pretendemos realizar uma recapitulação das definições de amor na tradição ocidental, embora não se possa negar o fato de que o tema foi objeto de reflexão e estudo de diferentes aéreas. Braz (2006), por exemplo, baseando-se em Edgar Morin e Humberto Maturana, pensa sobre a importância do amor tanto no surgimento e manutenção da espécie humana quanto para estruturação interna dos sujeitos humanos. Nota-se, portanto, que a questão do amor continua a inquietar os pesquisadores, e, no nosso caso, intriga-nos uma ação derivada: a perseguição.

Devemos iniciar a discussão com a pergunta: o que é o amor? Voltando ao mito de Diotima, proferido por Sócrates, podemos dizer que o amor é desejo, que "deseja aquilo de que é carente", pois, nesse mito, o amor é apresentado a partir da falta. Essa perspectiva vem ao encontro do que a Psicanálise (Freud, $1912 / 1996)^{1}$ nos ensina a respeito do amor, que só pode existir pela superação de sua vertente narcísica, superação que se dá pela aceitação da castração, isto é, pelo reconhecimento da falta, que abre lugar para a relação com o outro e para o desejo. O sujeito se torna capaz de amar ao sair da lógica narcísica e se

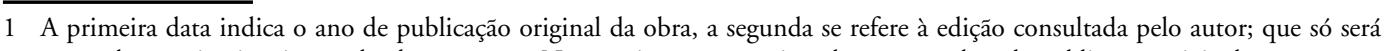
pontuada na primeira citação da obra no texto. Nas seguintes, será registrada apenas a data de publicação original. 
reconhecer como um ser de falta. Isto é, ao suportar admitir-se como faltante, o sujeito se torna capaz de reconhecer o outro como igualmente faltante, portanto, igualmente sujeito e, consequentemente, como um outro em seu caráter irredutivelmente alteritário e não mais como uma parte perdida de si mesmo a ser reassimilada para restaurar a suposta completude perdida.

Lacan apresenta diferentes concepçōes de amor. No seminário 1, "Os escritos técnicos de Freud", Lacan (1953-1954/1979) aborda o amor como dom ativo que visa ao ser do sujeito amado em sua particularidade. Essa vertente do amor é sustentada no plano simbólico.

Por outro lado, o amor-paixão visa ao outro como objeto. O amor na vertente imaginária é o amor narcísico, que implica uma relação especular. Ele visa a uma pretensa simetria amorosa entre os pares, ou seja, é sustentado pela ilusão de uma fusão.

Ainda no seminário 1, Lacan (1953-1954/1979) destaca que, no dom ativo do amor, ama-se algo que está além do objeto amado, ou seja, a falta. Se o sujeito se constitui por uma falta originária, a subjetividade é sustentada pela "falta a ser". O sujeito se dirige ao Outro $^{2}$ na intenção de suturar a falta que o estrutura. Complementando essa perspectiva, no seminário 4, "A relação de objeto", Lacan (1956-1957/1995) afirma que não existe maior signo de amor que o dom daquilo que não se tem. Amar é, portanto, dar o que não se tem, a saber, a falta.

Já no seminário 8, A transferência, Lacan (1960-1961/1992), ao recorrer ao Banquete de Platão, demonstra que o amor não é uma exigência de satisfação, mas uma partilha de faltas. $\mathrm{O}$ amor é, portanto, articulado à sublimação, pois pode ser uma criação a partir da falta.

No seminário 11, Os quatro conceitos fundamentais da psicanálise, Lacan (1964/1974) enfatiza novamente o dom ativo do amor, que se caracteriza pela troca da falta, isto é, cada um dá ao outro aquilo que não tem. A posição do amante é ativa, pois, ao colocar-se em falta, ele assume uma posição desejante, buscando algo para satisfazer-se. Nessa perspectiva, o amor envolve atividade e percebe-se que a falta está no cerne da questão do amor.

No seminário 20, Mais, ainda, Lacan (1972-1973/1982, p. 69) afirma que, "no amor, o que se visa é o sujeito". Assim, o amor localiza-se do lado do sujeito desejante, marcado pela perda primordial e capaz de dirigir-se ao Outro a fim de produzir sentido à sua experiência. $\mathrm{O}$ amor pode ser compreendido como uma tentativa de atribuição de sentido àquilo que, por estrutura, não tem sentido:

2 "O Outro é o lugar em que se situa a cadeia do significante que comanda tudo que vai poder presentificar-se do sujeito, é o campo desse vivo onde o sujeito tem que aparecer” (Lacan, 1964, p. 193-194) 
a inexistência da relação sexual. Segundo Lacan (1982, p. 62), "O que vem em suplência à relação sexual é precisamente o amor". Essa é a abordagem do amor pela via do real, o amor em sua função de véu em relação ao real, como suplência à inexistência da relação sexual. Desse modo, se o real é o impossível de simbolizar, ou seja, o furo estrutural, o amor seria um véu que permitiria recobrir e, ao mesmo tempo, abordar o real.

Consideramos que a subjetividade está presente nas interações virtuais, ou seja, os três registros da realidade psíquica, a saber, o real, o simbólico e o imaginário, estão envolvidos nas experiências do sujeito com a realidade virtual. As relações intersubjetivas estão mediadas pelo imaginário, que, por sua vez, ordena-se desde um ponto de referência simbólico. $O$ imaginário vela a dimensão real pulsional. Ele cumpre uma função ortopédica, criando a ilusão de completude. Mas, mesmo nas interações virtuais, o sujeito pode ser confrontado com o real como núcleo do seu ser, com algo que está para além do véu.

No seminário 4, Lacan (1956-1957/1995) comenta que o que é amado no objeto do amor encontra-se mais além, sendo a imagem do véu aquela que pode materializar essa relação de interposição: "O véu, a cortina diante de alguma coisa, ainda é o que melhor permite ilustrar a situação fundamental do amor" (Lacan, 1995, p. 157). O pensador adverte que, com a presença do véu, aquilo que está mais além, como falta, tende a se realizar como imagem. Posteriormente, no seminário 13, Lacan (1965-1966) dirá que o objeto a é real e tem como função ser suporte do desejo em sua dimensão ilusória.

Nas relaçôes virtuais, o amor não se sustenta na dimensão da falta, simbólica, mas na dimensão narcísica, fruto da cativação imaginária. Segundo Lacan (1979, p. 315), "Sem a palavra enquanto ela afirma o ser, há somente Verliebtheit, fascinação imaginária, mas não há amor. Há amor sofrido, mas não o dom ativo do amor".

O predomínio das imagens no ambiente virtual faz expandir o registro imaginário, provocando, como efeito, o enfraquecimento simbólico (Lima, 2003). Não há um encontro de corpos no ambiente virtual, mas de imagens, e essa prevalência do registro imaginário deixa exposta a imagem como constitutiva do eu, que sustenta a identificação imaginária. Para Lacan, o eu, constituído como uma estrutura passional, tem um núcleo paranoico que leva o sujeito a projetar no outro o que é dele. Assim, os relacionamentos virtuais são especulares, narcísicos, fazendo emergir a ilusão de completude, a rivalidade, e a competitividade, e a agressividade (Lima, 2003), que surge como forma de rompimento da alienação imaginária como forma de destruir aquele que é a sede da alienação do eu. 
O simbólico tem uma função pacificadora que abre a via desejante para o sujeito. A castração introduz no simbólico a diferença, desfazendo a ilusão da unidade imaginária. $\mathrm{O}$ encontro presencial leva à aceitação da castração na dimensão de falta, pois aponta para a discordância entre o que se projeta no outro e o que se encontra. No ambiente virtual, por sua vez, o sujeito pode utilizar a tela do computador tentando se evadir da castração, como forma de não se haver com a impossibilidade de complementariedade entre os sexos. Assim, as telas dos dispositivos tecnológicos servem como um aparato de intermediação entre os corpos, deixando-os em suspenso, permitindo a criação de um cenário para a satisfação imaginária, elidindo a castração na dimensão de falta. Se o simbólico, como função, encontra-se debilitado no ambiente virtual, ele não atua como limite, o que pode levar à passagem do imaginário ao real sem nenhuma mediação. Nesse caso, o meio virtual pode facilitar a passagem ao ato, sendo este um grande risco na atualidade, quando acompanhamos notícias de crimes e suicídios motivados pelas redes sociais.

Podemos dizer que as dimensões de espaço e tempo são as grandes organizadoras da psique e da experiência humana, sendo por meio delas que se opera, de modo mais exemplar, a castração, pois estabelecem limites à ação e realização humanas, materializando sua finitude. Tendo isso em vista, um bom exemplo de como as tecnologias flexibilizam/liquefazem essas dimensões, tornando-as menos eficazes em sua função limitadora/orientadora, é o telefone celular. $\mathrm{O}$ celular permite falar com o outro a qualquer hora e em qualquer lugar. $\mathrm{O}$ que nasce dessa possibilidade é um dever, isto é, uma nova lei pela qual o outro tem de estar todo o tempo a meu dispor e eu ao dispor do outro, já que, uma vez que esse aparelho permite o contato irrestrito, não parece haver justificativa para que o outro não se apresente/atenda quando eu o chamar e vice-versa. Não apenas perde-se a dimensão do espaço, já que o contato pode se dar em qualquer lugar, desde que cada um esteja portando seu aparelho, como se perde a dimensão do tempo, da espera, do adiamento da "satisfação", já que o outro não somente pode e, portanto, deve me atender (e eu atendê-lo), não obstante a distância, mas também ele (e eu) deve me atender/responder/satisfazer imediatamente. Passa a ser dever de cada um não apenas estar acessível em qualquer lugar, mas também a qualquer hora, negando-se, com isso, de forma muito eficaz, a existência inexorável da falta. Mas quais os efeitos desse controle virtual sobre o outro e sobre a própria vivência do amor?

Apresentamos aqui algumas possíveis reflexões sobre o amor, entre tantas. Todavia, aqui, interessa-nos pensar as vicissitudes do amor no mundo contemporâneo, especificamente sobre os impactos da expansão das redes sociais nas concepções e maneiras de amar nos nossos dias. Assim, investimos na pesquisa 
"Relacionamentos amorosos de adolescentes e a internet", com financiamento do CNPq e da Fapemig, para a qual, antes de partir para pesquisa de campo e escutar os jovens, realizou-se uma pesquisa de levantamento bibliográfico, utilizando os recursos da internet sobre publicaçôes científicas na área da Psicologia acerca do tema do amor.

O procedimento metodológico de pesquisa foi a busca no indexador Pepsic da produção científica no campo da Psicologia e áreas afins sobre o referido tema com o recorte temporal de três anos (2010 a 2013), e, ao se utilizarem como palavras-chave os termos "amor e Psicologia" e "amor e internet", foram encontrados 86 artigos. Organizamos esse total em sete grupos:

a) amor e feminilidade (Costa, Ferraz \& Ribeiro, 2013; Zalcberg, 2012);

b) amor e maternidade (Menezes \& Dias, 2011; Oliveira, 2007);

c) amor e a dinâmica psíquica (Freitas \& Rudge, 2011; Arreguy, 2004);

d) amor e perda (Levy \& Gomes, 2011);

e) amor e clínica (Brito \& Besset, 2008);

f) amor e educação (Alves, Alencar \& Ortega, 2012);

g) amor e sociedade (Araujo, 2002). A diversidade de discussões em torno do tema do amor tornou, entretanto, inviável a tarefa de produzir um texto no formato de revisão crítica de literatura sobre a produção científica nas revistas disponíveis no Pepsic.

É interessante ressaltar, contudo, que apenas três artigos, dentre os encontrados no indexador, retratavam o tema dos impactos das redes virtuais sobre o amor. Guedes e Assunção (2006), que apresentavam hipótese da falência do amor romântico em uma sociedade individualista e narcisista, Dela Coleta, Dela Coleta e Guimarães (2008) e Donnamaria e Terzis (2009).

Dela Coleta et al. (2008) realizaram uma pesquisa com 50 usuários brasileiros da internet, com o objetivo de entenderem as novas modalidades de relacionamento amoroso oferecidas pela internet. Verificou-se que os sujeitos da pesquisa acreditam que ela pode propiciar o início de um contato, mas a continuação do vínculo depende de um encontro presencial. No entanto, $64 \%$ dos entrevistados declararam que já tiveram relacionamento amoroso virtual e $68 \%$ acreditam que podem ser bem-sucedidos em um relacionamento amoroso pela internet. Apesar da alta porcentagem que aposta no amor pela 
internet, os pesquisadores concluíram que esse veículo não acarretou mudanças comportamentais no âmbito das relações amorosas, ainda que acreditem ser necessária a realização de novas pesquisas:

A partir dos resultados obtidos, concluiu-se que não houve mudanças comportamentais e afetivas radicais com essa nova forma de relacionamento, mas os dados sugerem a importância de mais pesquisas para esclarecer as consequências do relacionamento virtual e do uso exagerado da Internet como forma de comunicação social (Dela Coleta et al., 2008, p. 277).

A pesquisa de Donnamaria e Terzis (2009), por fim, escutou casais cujos vínculos originaram-se de relacionamentos mediados pela internet e, mais uma vez, o tema do encontro face a face se impôs como condição para a manutenção e o desenvolvimento da relação.

O tema da articulação entre o amor e a internet ainda carece de muitos estudos, pois essa é uma relação que gera várias novas possibilidades comportamentais bem como sua intensificação.

\section{O AMOR E O “STALKEAR”: INTERPRETAÇÕESS POSSÍVEIS}

A escassa bibliografia sobre amor e redes sociais confirmou a relevância de nosso estudo, surgindo, então, uma nova questão: a distância vivenciada como realidade concreta no encontro de amor virtual facilitaria a relação?

Uma questão que está no cerne das discussões sobre os relacionamentos virtuais diz respeito à distância. Haveria uma maior aproximação ou um maior distanciamento entre as pessoas através da realidade virtual? Nesse ponto, pensamos na parábola/metáfora schopenhaueriana sobre o amor, reconstruída por Freud (1921/1977):

Um grupo de porcos-espinhos apinhou-se apertadamente em certo dia frio de inverno, de maneira a aproveitarem o calor uns dos outros e assim salvarem-se da morte por congelamento. Logo, porém, sentiram os espinhos uns dos outros, coisa que os levou a se separarem novamente. E depois, quando a necessidade de aquecimento os aproximou mais uma vez, o segundo mal surgiu novamente. Dessa maneira, foram impulsionados, para trás e para frente, de um problema para o outro, até descobrirem uma distância intermediária, na qual podiam toleravelmente coexistir (Schopenhauer, 1851, citado por Freud, 1921, p. 128).

Diante desse dilema, poderíamos acalentar a ideia de que as redes sociais podem oferecer a distância ideal entre o aquecimento e o respeito à intimidade. 
No entanto, ao pensarmos em dois fenômenos comumente relatados por amantes, o ciúme e a perseguição, podemos questionar em que medida a rede oferece a distância ideal. Como vimos, a predominância do registro imaginário nas relaçôes virtuais reforça a tendência narcisista: o eu se constitui numa relação de identificação imaginária com o outro, que demarca a dimensão de alienação estruturante da subjetividade. Desde a origem, dada a sua organização passional (Lacan, 1995, p. 116), o eu está marcado pela agressividade que, ligada à relação narcísica, caracteriza a formação do eu (Lacan, 1995, p. 118). Assim, a "proximidade virtual" promove as relações especulares, exacerbando a agressividade e a rivalidade estruturais.

Nessa perspectiva, o outro é tanto parte "do eu" quanto oferece uma ameaça à sua existência. A perseguição ao parceiro parece se apoiar na dificuldade em reconhecer no outro a sua diferença, sustentando-se a função simbólica na falta, no reconhecimento da impossibilidade de ter o outro como complemento de si. O reconhecimento da falta no Outro implica o reconhecimento da própria falta, desfazendo-se a ilusão de que o outro deve preenchê-la. O encontro com o outro sexo demonstra, pois, que a diferença sexual não promove um ideal de simetria e complementaridade, não sendo possível controlar o desejo do Outro. Existe uma distância ética entre o sujeito e o outro, necessária para a sustentação do laço social.

Com o advento das redes sociais, o comportamento de perseguir parceiros, ex-parceiros ou pretendentes não só é reforçado como ganha um novo horizonte: com elas, torna-se possível vasculhar todas as suas páginas, vigiar de perto seus passos sem ser descoberto. Esse velho/novo fenômeno (re)inaugurado pelos dispositivos da internet, a perseguição, é denominado na atualidade como "stalkear" (do inglês, stalking).

O fenômeno do "stalkear" ("Guia da stalker", 2017) nas redes sociais ainda não se apresentou como objeto de estudo pela Psicologia no Brasil, mas é muito conhecido dos usuários das redes sociais, havendo, inclusive, páginas no Facebook dedicadas à discussão do tema, a exemplo da página denominada Amar e stalkear. Encontramos, ainda, na rede virtual, um guia para "stalkeadores", ensinando regras básicas e truques para não serem descobertos.

Ao observar o fenômeno, Roncolato (2014) escreve na revista "Galileu" um artigo intitulado "O que leva alguém a stalkear o companheiro no Facebook". No artigo, o autor apresenta um estudo publicado na "Cyberpsychology, behaviorand social networking" (Fox \& Warber, 2014), coordenado pela pesquisadora doutora em Comunicação Jesse Fox, da Universidade de Ohio, nos Estados Unidos. No estudo, foi possível entrevistar 328 estudantes, com idades 
entre 18 e 48 anos sobre o tema da vigilância eletrônica dos parceiros (Fox \& Warber, 2014). A pesquisa revela que os sujeitos mais inseguros e com medo de serem traídos tendem a usar mais do recurso da vigilância eletrônica.

Sabemos que esses sentimentos de insegurança e medo, assim como o comportamento devigiaro parceiro, nãosão exclusividadeda Contemporaneidade. Inúmeros são os registros na literatura psiquiátrica, psicanalítica e artística sobre pessoas que não conseguem deixar de pensar em seus amores, principalmente aqueles que não são correspondidos. Apontando um fracasso da ação do tempo, que, no senso comum, é tido como o responsável por aliviar a dor da ausência de um objeto querido, tais registros mostram que os amantes-constantes, não raramente, tentam ser participantes da vida do amado de forma cada vez mais expressiva.

Adèle Hugo, filha do escritor francês Victor Hugo, teve poeticamente sua história retratada no filme $A$ história de Adèle $H$ (2017), dirigido por Françoise Truffaut (Berbet $\&$ Truffaut, 1975). Apaixonada por um tenente inglês, o oficial Pinson, Adèle Hugo desconsidera a inconstância de seu amado, afasta-se de sua própria família e coloca-se a persegui-lo pelo Canadá e, posteriormente, pelas Ilhas Barbados. Não correspondida em seu amor, Adèle sofre e deteriora-se mentalmente em um enlouquecimento apaixonado enquanto persegue o oficial. Faz de uma fotografia do tenente seu objeto religioso e, ajoelhada diante da representação fotográfica do homem que não lhe quer, expressa adoração e reverência. É interessante perceber que, como observa Bougon (2013), a barreira linguística dificulta a interação da personagem com seu amado: "Isolada pela língua inglesa que ela pouco conhece e pela rejeição de Pinson, mas também pela sua incapacidade de suportar a vida social, Adèle se comunica principalmente através de cartas" (p. 262).

Richard Von Krafft-Ebing, em seus estudos sobre psicopatologia sexual iniciados em 1886, incluiu, no cenário médico, a discussão sobre o fenômeno do amor que não cessa e a admiração excessiva ao escrever sobre mulheres que viajavam pela Europa perseguindo atores que amavam ("Amor obsessivo", 2010).

De acordo com Segal (1989), há algumas manifestações patológicas do amor: ninfomania (furor uterinus), erotomania (amor insanus) e melancolia erótica, tendo o psiquiatra francês Gaëtan Gatian de Clèrambault dado destaque à erotomania ao descrever alguns casos em 1921. Segundo o autor, nos pacientes erotômanos, um tipo específico de delírio erótico desacompanhado de outras patologias psiquiátricas é identificado, e, à semelhança do que ocorre nas psicoses passionais por ele apresentadas em 1919-1920, uma vivência de "paixão mórbida” pode ser percebida (Calil \& Terra, 2005). 
A erotomania, contudo, não é um fenômeno exclusivo da psicose. Tendo como referência as discussões de Freud sobre a feminilidade, Santos e Sartori (2007, p. 20) observam que "Amar demais, enlouquecer de amor, é uma vicissitude comum na vida erótica feminina, visto que o supereu - herdeiro do Complexo de Édipo - das mulheres nunca é tão impessoal e tão independente de suas fontes libidinais".

O amor erotomaníaco é feminino, considerando-se o feminino um dos modos de se posicionar na partilha sexual (Lacan, 1982). O lado masculino da partilha sexual caracteriza-se, por sua vez, pela submissão do gozo (excedente pulsional) ao registro simbólico. O lado feminino é caracterizado pela emergência de um gozo não subordinado ao significante, ou seja, um gozo que "ultrapassa” o sujeito (Soler, 2005). Marcado pelo excesso, o amor feminino é ciumento porque se prende às características de seu gozo e, por ser heterogêneo à estrutura da linguagem, ele se apresenta de forma desmedida, arrebatadora. Esse tipo de amor está mais ou menos presente na maioria dos sujeitos, a despeito das diferenças de gênero, visto que o feminino e o masculino para Lacan não correspondem aos gêneros sexuais, mas demarcam dois tipos de gozo, um todo regulado pela linguagem e outro fora dos seus domínios.

A irrupção desse amor enlouquecido e desmedido é favorecida pelo enfraquecimento do registro simbólico, que não atua como limite ao imaginário. Dessa forma, a passagem do imaginário ao real ocorre sem a mediação de nenhuma instância, surgindo, então, a dimensão pulsional sem a mediação simbólica.

Entre os sinais da erotomania, as incessantes tentativas de contato com o objeto de amor despertam-nos a atenção, pois, nesses casos, uma espécie de caça é estabelecida e a ausência do objeto é sentida com grande incômodo. Tal comportamento, em inglês, é chamado stalking e diz respeito ao jeito cuidadoso e planejado de o caçador se aproximar da caça. O stalker insiste em visualizar seu objeto e, por mais que seja rejeitado, a aproximação por meio de cartas, e-mails e telefonemas é comum. Trata-se de um rastreamento repetido e intencional que pode ameaçar a integridade física e, ou, psicológica daquele que é rastreado, perseguido ou caçado (Voß \& Hoffmann, 2002).

Em um mundo onde o acesso à realidade parece alargado com o uso das redes virtuais/sociais, o "stalkeador" ganha mais instrumentos para operar sua vigilância. As redes virtuais ampliam a realidade, oferecendo, pois, maior acessibilidade ao objeto "amado". Nas páginas do Facebook, o sujeito rejeitado tem acesso irrestrito ao cotidiano do objeto amado, podendo acompanhar viagens, festas, novos relacionamentos. Esse acesso ilimitado é, entretanto, limitado pelo sujeito "stalkeado", que pode optar por postar apenas as alegrias, os bons momentos 
de sua vida, trazendo a sensação ilusória de uma vida perfeita, possivelmente provocando mais a ira e o aprisionamento do "stalkeador" ao objeto amado. Freud (1915/1996) revela que, no processo de elaboração da perda, é possível se posicionar no campo do luto, no qual o mundo fica esvaziado, ou no campo da melancolia, em que o mundo se mantém rico e o eu esvaziado. Talvez o acesso ilimitado às alegrias do amado postadas na rede social possa dificultar o trabalho de luto.

Nesse ponto, parece-nos pertinente enfatizar que a reflexão sobre a possível dificuldade do "stalkeador" em realizar um trabalho de luto não equivale a uma proposta diagnóstica. Ao escrever $A$ perda da realidade na neurose e na psicose, Freud (1924/1996) esclarece que, nos dois tipos de configuração mental (neurose e psicose), há uma perturbação na relação do paciente com a realidade. $\mathrm{Na}$ neurose, segundo o autor, há um afrouxamento do laço do sujeito com a realidade, enquanto, no caso da psicose, dá-se um corte radical desse laço. Seja por meio do delírio ou das fantasias, a relação dos sujeitos com a realidade não é livre de interferências.

Julga-se importante lembrar esse ponto da teoria freudiana, porque nele se evidencia a impossibilidade de completa polarização entre patologia e normalidade, o que contribui para uma reflexão sobre o fenômeno contemporâneo do "stalkear"; não nos é possível identificar o stalker como característico de uma específica estrutura subjetiva. A escuta da especificidade que essa ação adquire para cada sujeito bem como a relação desta ação (caçar, perseguir) com a história clínica e os elementos transferenciais de cada caso são fundamentais para o estabelecimento de um diagnóstico clínico.

\section{CONSIDERAÇÕES FINAIS}

Baseados na declaração de Jacques Lacan sobre o amor no inédito seminário "O desejo e sua interpretação" (1958-1959/2016) e também no seminário 8, "A transferência” (Lacan, 1992) (“amar é dar o que não se tem”), podemos afirmar que o amor se sustenta na falta.

Com base na psicanálise, fizemos duas leituras do fenômeno do "stalkear". Na primeira, ao tomarmos como referência os três registros da realidade psíquica (real, simbólico e imaginário), consideramos que a realidade virtual marca a prevalência do registro imaginário, que acarreta relações imaginárias. Há, portanto, uma predominância do amor na sua dimensão imaginária; um amor narcísico que visa à complementariedade entre os pares. 
A ilusão da completude narcísica é facilitada pela internet quando ela rompe "as distâncias" físicas. É viável aos usuários se falarem a qualquer hora, estando em qualquer lugar, fazendo com que o outro esteja próximo demais. Essa proximidade, contudo, é puramente virtual. A proximidade dos corpos denuncia a impossibilidade da união complementar dos parceiros enquanto cada um busca no outro o objeto da sua fantasia e o que é de fato encontrado no outro não coincide com essa fantasia.

A "proximidade virtual" promove, pois, as relações especulares, exacerbando a agressividade e a rivalidade estruturais. Nessa perspectiva, o outro é tanto parte do "eu" quanto oferece uma ameaça à sua existência, e a perseguição ao parceiro parece apoiar-se na dificuldade em reconhecer no outro a sua diferença.

As tecnologias virtuais, e as redes sociais em especial, permitem que acompanhemos a vida cotidiana do outro, fazendo com que sua vida "pertença ao sujeito". Afinal, o que é postado nas redes sociais está público e, desse modo, o outro me dá acesso à sua vida, mesmo que, em alguns casos, mais restritamente. Se o sujeito sente que há uma "permissão" para fazer parte da vida do outro ilimitadamente, ou seja, se os limites entre o eu e o outro estão mais tênues pela virtualidade, por que não o fazer?

Numa segunda leitura, consideramos que o amor erotomaníaco encontra um terreno fértil para a sua expansão através das redes sociais virtuais. Esse amor sem limites, desmedido, absoluto, é sustentado pela dimensão pulsional, pelo gozo que escapa à simbolização. A pulsão encontra, no ambiente virtual, meios para a sua satisfação. Quando o simbólico está enfraquecido, ele não atua como limite, favorecendo a passagem do imaginário ao real sem a mediação de nenhuma instância. Assim, o meio virtual propicia as passagens ao ato, como é possível acompanhar na mídia os relatos de crimes e agressões desencadeados pelas redes sociais.

Dessa maneira, podemos pensar o fenômeno do "stalkear" nas redes sociais facilitado pela própria lógica de funcionamento dessas redes e das possibilidades que elas abrem aos sujeitos. Ele se apresenta como um expressivo campo de investigação e pesquisa aos clínicos, teóricos e trabalhadores da Psicologia e da Psicanálise. 


\section{REFERÊNCIAS}

Alves, A. D., Alencar, H. M. \& Ortega, A. C. (2012). Exemplos sobre a importância do amor: estudo com crianças no contexto da moralidade. Temas em Psicologia, 20(1), 261-272. Recuperado a partir de http://pepsic.bvsalud. org/scielo.php?script=sci_arttext\&pid=S1413-389X2012000100019\&lng=pt \&nrm=iso

Amar e stalkear (2017). [S. 1.]: Facebook, 2017. Recuperado a partir de https:// www.facebook.com/search/str/Amar+e+stalkear/keywords_search

Amor obsessivo. (2010). Mente e cérebro. Recuperado a partir de http://www2. uol.com.br/vivermente/reportagens/amor_obsessivo.html

Araujo, M. F. (2002). Amor, casamento e sexualidade: velhas e novas configurações. Psicologia: Ciência e Profissão, 22(2), 70-77. Recuperado a partir de http://pepsic.bvsalud.org/scielo.php?script=sci_arttext\&pid=S141498932002000200009\&lng=pt\&nrm=iso

Arreguy, M. E. (2004). Dois romances, tempos distintos: uma reflexão sobre o amor e o ciúme na atualidade. Revista Mal-Estar e Subjetividade, 4(1), 112130. Recuperado a partir de http://pepsic.bvsalud.org/scielo.php?script=sci_ arttext\&pid=S1518-61482004000100006\&lng=pt\&nrm=iso

Berbert, M. (Pordução) \& Truffaut, F. (Direção). (1975). L'histoire d'Adèle H. [Filme cinematográfico]. Paris: Les Films du Carrosse.

Bougon, P. (2013). As cartas de crédito em "A História de Adèle H", de Françoise Truffaut (1975). Itinerários, 36, 259-275.

Braz, A. L. N. (2006). Reflexões sobre as origens do amor no ser humano. Psicologia para América Latina, 5. Recuperado a partir de http://pepsic.bvsalud. org/scielo.php?script=sci_arttext\&pid=S1870-350X2006000100006\&lng=pt \&nrm=iso

Brito, B. P. M. \& Besset, V. L. (2008). Amor e saber na experiência analítica. Revista Mal-Estar e Subjetividade, 8(3), 681-703. Recuperado a partir de http://pepsic.bvsalud.org/scielo.php?script=sci_arttext \&pid=S151861482008000300006\&lng=pt\&nrm $=$ iso

Calil, L. C. \& Terra, J. R. (2005). Síndrome de De Clèrambault: uma revisão bibliográfica. Revista Brasileira de Psiquiatria, 27(2), 152-156. 
Costa, A. M. M., Ferraz, M. A. L. \& Ribeiro, V. N. F. (2013). O amor, o feminino e a escrita. Tempo Psicanalítico, 45(1), 29-38. Recuperado a partir de http://pepsic.bvsalud.org/scielo.php?script=sci_arttext\&pid=S010148382013000100003\&lng=pt\&nrm=iso

Dela Coleta, A. S. M., Dela Coleta, M. F. \& Guimarães, J. L. (2008). O amor pode ser virtual? $\mathrm{O}$ relacionamento amoroso pela Internet. Psicologia em Estudo, 13(2), 277-285. Recuperado a partir de http://www.scielo.br/scielo. php?script=sci_arttext\&pid=S1413-73722008000200010\&lng=pt\&nrm=iso

Donnamaria, C. P. \& Terzis, A. (2009). O amor caiu na rede: sobre a procura de parceiro e a evolução de vínculos amorosos na internet. Revista da Spagesp, 10(2), 45-49. Recuperado a partir de http://pepsic.bvsalud.org/scielo. php?pid=S1677-29702009000200008\&script=sci_arttext

Fox, J. \& Warber, K. M. (2014). Romantic relationship development in the age of Facebook: an exploratory study of emerging adults' perceptions, motives, and behaviors. Cyberpsychology, Behavior, and Social Networking, 17(1), 3-7.

Freitas, A. L. \& Rudge, A. M. (2011). O supereu entre o amor e o gozo. Tempo Psicanalitico, 43(2), 244-267. Recuperado a partir de http://pepsic.bvsalud. org/scielo.php?script=sci_arttext\&pid=S0101-48382011000200001\&lng=pt \&nrm=iso

Freud, S. (1912). Contribuiçõos à psicologia do amor. In J. Salomão (Trad.), Edição standard brasileira das obras psicológicas completas de Sigmund Freud (Vol. 11, pp. 163-173). Rio de Janeiro: Imago, 1996. (Publicado originalmente em 1912).

Freud, S. (1915). Luto e melancolia. In J. Salomão (Trad.), Edição standard brasileira das obras psicológicas completas de Sigmund Freud (Vol. 14, pp. 245279). Rio de Janeiro: Imago, 1996. (Publicado originalmente em 1915).

Freud, S. (1921). Psicologia de grupo e a análise do ego. In J. Salomão (Trad.), Edição standard brasileira das obras psicológicas completas de Sigmund Freud (Vol. 18, pp. 89-181). Rio de Janeiro: Imago, 1977. (Publicado originalmente em 1921).

Freud, S. (1924). A perda da realidade na neurose e na psicose. In J. Salomão (Trad.), Edição standard brasileira das obras psicológicas completas de Sigmund Freud (Vol. 19, pp. 203-209). Rio de Janeiro: Imago, 1996. (Publicado originalmente em 1915). 
Guedes, D. \& Assunção, L. (2006). Relações amorosas na contemporaneidade e indícios do colapso do amor romântico (solidão cibernética?). Revista Mal-Estar e Subjetividade, 6 (2), 396-425. Recuperado a partir de http://pepsic.bvsalud.org/scielo.php?script=sci_ arttext\&pid=S151861482006000200007\&lng=pt\&nrm=iso

Guia da stalker: tudo o que você precisa saber para se dar bem nas redes sociais (2017) Recuperado a partir de https://www.obaoba.com.br/pegacao/noticia/ guia-da-stalker-tudo-o-que-voce-precisa-saber-para-se-dar-bem-nas-redessociais

Lacan, J. (1958-59). O seminário: Livro 6: o desejo e sua interpretação Rio de Janeiro: Jorge Zahar, 2016. (Publicado originalmente em 1958-1959).

Lacan, J. (1965-1966). O seminário: Livro 13: o objeto da psicanálise. Inédito.

Lacan, J. (1964). O seminário, Livro 11: os quatro conceitos fundamentais da Psicanálise. Rio de Janeiro: Jorge Zahar, 1974. (Publicado originalmente em 1964).

Lacan, J. (1953-1954). O seminário: Livro 1: os escritos técnicos de Freud. Rio de Janeiro: Jorge Zahar, 1979. (Publicado originalmente em 1953-1954).

Lacan, J. (1972-1973). O seminário: Livro 20: mais, ainda. Rio de Janeiro: Jorge Zahar,1982. (Publicado originalmente em 1972-1973).

Lacan, J. (1960-1961). O seminário: Livro 8: a transferência. Rio de Janeiro: Jorge Zahar, 1992. (Publicado originalmente em 1960-1961).

Lacan, J. (1956-1957). O seminário: Livro 4: a relação de objeto. Rio de Janeiro: Jorge Zahar, 1995. (Publicado originalmente em 1956-1957).

Levy, L. \& Gomes, I. C. (2011). Relações amorosas: rupturas e elaborações. Tempo Psicanalitico, 43(1), 45-57. Recuperado a partir de http://pepsic.bvsalud.org/ scielo.php?script=sci_arttext\&pid=S0101-48382011000100003\&lng=pt\&nr $\mathrm{m}=\mathrm{iso}$

Lima, N. L. (2003). Fascínio e alienação no ciberespaço: uma leitura psicanalítica. (Dissertação de Mestrado). Universidade Federal de Minas Gerais, Faculdade de Educação, Belo Horizonte.

Menezes, K. L. \& Dias, C. M. S. B. (2011). Mães doadoras: motivos e sentimentos subjacentes à doação. Revista Mal-Estar e Subjetividade, 11(3), 935- 
965. Recuperado a partir de http://pepsic.bvsalud.org/scielo.php?script=sci_ arttext\&pid=S1518-61482011001300003\&lng=pt\&nrm=iso

Oliveira, A. R. D. (2007). Amor primitivo, amor verdadeiro. Revista Brasileira de Psicanálise, 41(4), 89-102. Recuperado a partir de http://pepsic.bvsalud. org/scielo.php?script=sci_arttext\&pid=S0486-641X2007000400009\&lng=pt \&nrm=iso

Platão. (2005). O banquete. In Platão. Apologia de Sócrates. São Paulo: Martin Claret.

Roncolato, M. (2014). O que leva alguém a stalkear o companheiro no Facebook. Revista Galileu Online. Recuperado a partir de http://revistagalileu.globo.com/ Revista/Common/0,EMI342460-17770,00-O+QUE+LEVA+ALGUEM+A + +STALKEAR+O+COMPANHEIRO+NO+FACEBOOK.html

Santos, T. C. \& Sartori, A. P. (2007). Loucos de amor! Neuroses narcísicas, melancolia e erotomania feminina. Tempo Psicanalítico, 39, 13-33. Recuperado a partir de http://www.spid.com.br/revistas/r39/02\%20TP39\%20-\%20 Tania\%20Coelho\%20dos\%20Santos\%20e\%20Ana\%20Paula\%20Sartori.pdf

Segal, J. H. (1989). Erotomania revisited: from Kraepelin to DSM-III-R. The American Journal of Psychiatry, 146(10), 1261-1266.

Soler, C. (2005). O que Lacan dizia das mulheres. Rio de Janeiro: Zahar.

Voß, H. G. W. \& Hoffmann, J. (2002). Zur Phänomenologie und Psychologie des Stalking: eine Einführung. Polizei \& Wissenschaft (ThemenheftStalking), 4, 4-14.

Zalcberg, M. (2012). A devastação: uma singularidade feminina. Tempo Psicanalítico, 44 (2), 468-475. Recuperado a partir de http://pepsic.bvsalud. org/scielo.php?script=sci_arttext\&pid=S0101-48382012000200013\&lng=pt \&nrm=iso 